\title{
Estudo da imagem sócio-ambiental urbana de Foz do Iguaçu-PR
}

\author{
Study of urban socio-environmental image of Foz do lguaçu-PR \\ Douglas Felipe Galvão', Ana Paula Ghizzo Alves², Juliana Cristina Kreutz³, \\ Paulo Rodrigo Stival Bittencourt ${ }^{4}$, Michelle Budke Costa \\ ' Mestrando em Tecnologias Ambientais - Universidade Tecnológica Federal do Paraná, UTFPR - Paraná \\ ${ }^{2}$ Graduanda em letras português-espanhol - Universidade Federal da Fronteira Sul, UFFS - Paraná \\ ${ }^{3}$ Graduanda em Química Licenciatura - Universidade Tecnológica Federal do Paraná, UTFPR - Paraná \\ 4,5 Doutores em Química - Universidade Tecnológica Federal do Paraná, UTFPR - Paraná
}

\section{Resumo}

Foz do Iguaçu, município de grande porte localizado no oeste do Estado do Paraná, conta com uma das sete maravilhas da natureza e está entre as cidades turísticas brasileiras mais visitadas. O objetivo deste trabalho foi o estudo da imagem sócio-ambiental do município através da percepção ambiental dos habitantes do município. A coleta dos dados ocorreu no ano de 2012 por meio de questionário e entrevista sendo aplicados 162 questionários a moradores de diversos bairros localizados na zona urbana do município de Foz do Iguaçu. Os resultados obtidos propiciou o estudo da imagem sócio-ambiental, estabelecendo as paisagens agradáveis e desagradáveis, objetos e singularidades que estes percebem na cidade e nos bairros onde residem. Os entrevistados acreditam na importância da preservação do meio ambiente, onde a maioria concebe o meio ambiente como áreas verdes e florestas e consideram a preservação, as paisagens, praças e qualidade ambiental da cidade como deficientes.

Palavras-chaves: Foz do Iguaçu, Percepção ambiental, Educação ambiental.

\begin{abstract}
Foz do Iguacu, a large municipality located in western Parana State, has one of the seven wonders of nature and is among the most visited tourist Brazilian cities. The objective of this work was to study the socio-environmental image of the city through environmental awareness of inhabitants of the municipality. Data collection occurred in 2012 through a questionnaire and interview 162 questionnaires being applied to residents of many neighborhoods located in the urban area of the city of Foz do Iguaçu. The results enabled the study of socio-environmental image, establishing the pleasant and unpleasant landscapes, objects and realize that these singularities in the city and the neighborhoods where they live. Respondents believe in the importance of preserving the environment, where the majority conceives the environment as green areas and forests and consider the preservation, landscapes, parks and environmental quality of the city as disabled.
\end{abstract}

Keywords: Foz do Iguaçu, Environmental Perception, Environmental Education. 


\section{INTRODUÇÃO}

A temática ambiental ficou muito evidente no Brasil, principalmente após a Conferência das Nações Unidas sobre o Meio Ambiente e Desenvolvimento (Eco-92), realizada no Rio de Janeiro em 1992. No entanto, a forma como os brasileiros reconhecem e percebem o meio ambiente ainda não é muito conhecida (FERNANDES, et al., 2005). Isto deixa evidente a necessidade de trabalhos para se conhecer a assimilação da temática ambiental por parte dos brasileiros.

Estudos sobre percepção ambiental norteiam ações para o melhor conhecimento da temática ambiental, para reintegração do homem ao meio natural e para mudanças de atitudes e pensamentos, com vistas a preservação ambiental. A educação ambiental de acordo com Philippi Jr e Pelicioni $(2005$, p.3) "vai formar e preparar cidadãos para a reflexão crítica e para uma ação social corretiva ou transformadora do sistema, de forma a tornar viável o desenvolvimento integral dos seres humanos".

O presente estudo teve como objetivo analisar a percepção ambiental entre os habitantes do município de Foz do Iguaçu, procurando conhecer como as pessoas percebem os problemas ambientais e as paisagens ambientais, tanto do bairro onde residem, como do município em toda sua extensão estabelecendo assim, baseado em Lynch (1999) um novo método para formar, através da percepção dos habitantes, a imagem da cidade.

\section{EDUCAÇÃO AMBIENTAL}

De acordo com Ruscheinsky (2002, p. 38) o meio ambiente pode ser definido como "o conjunto dos processos abióticos e bióticos existentes na Terra passíveis da influência da ação humana". O componente humano reconhece o meio ambiente como o "espaço-tempo histórico ocupado pelos entes no qual transcorre a vida dos seres humanos" (RUSCHEINSKY, 2002).

O aparecimento do Homo sapiens é considerado o marco do início da degradação ambiental do planeta (PHILIPPI JR., ROMÉRO, BRUNA, 2004). A partir de então, ocorreram três mudanças culturais: a Revolução Agrícola, a Revolução Industrial Médica e a Revolução da Informação-globalização. Estas transformações aumentaram muito o impacto que o homem causava no meio ambiente, pois permitiram o crescimento da população, principalmente pela disponibilidade de recursos e aumento da expectativa de vida (MILLER JR, 2008).

Muitos estudos demonstram que as alterações ambientais impostas pelos padrões de consumo e de produção que existem em nossa sociedade modificaram os ambientes naturais, causaram poluição, consumiram recursos exageradamente, causando danos negativos à qualidade de vida da população (PHILIPPI JR, PELICIONI, 2005).

Para reverter a situação de degradação do planeta, a ideia do Desenvolvimento Sustentável prevê a conscientização da população e mudança de pensamento com relação a padrões de consumo, preservação ambiental e desenvolvimento econômico.

Levando-se em conta a legislação no Brasil, o artigo 225 da Constituição Federal, incumbe o Poder Público de promover a Educação ambiental no ensino, em todos os níveis, e conscientização da população quanto à preservação do meio ambiente (PHILIPPI JR, PELICIONI, 2005). Com isso, em 27 de abril de 1999 foi sancionada a Lei Federal n 9.795, criando a Política Nacional de Educação Ambiental. Esta Lei concebe a educação ambiental como

os processos por meio dos quais o indivíduo e a coletividade constroem valores sociais, conhecimentos, habilidades, atitudes e competências voltadas para a conservação do meio ambiente, bem de uso comum do povo, essencial à sadia qualidade de vida e sua sustentabilidade (BRASIL, 1999).

No Brasil, desde 1981, a partir da sanção da Lei Federal nº 6.938, que dispõe sobre a Política Nacional do Meio Ambiente, que a Educação Ambiental é considerada um alicerce, estando presente em todos os níveis de ensino, incluindo-se a comunidade, todos engajados na defesa do meio ambiente (PHILIPPI JR, PELICIONI, 2005).

No final da década de 90, início do século XXI, é reintroduzida nos currículos das escolas, compondo a parte diversificada e flexibilizada do currículo de ensino. 


\section{PERCEPÇÃO AMBIENTAL}

Castro, Silva e Silva (2009, p. 3) afirmam a percepção ambiental

"como a forma pela qual os seres humanos ficam a par dos objetos e transformações que se manifestam ao seu entorno, sendo estudada com o intuito de entender a estreita relação homem-ambiente".

Assim é possível perceber a importância de se conhecer as opiniões da população acerca dos temas ambientais, ou seja, afirma-se a importância da percepção ambiental para a educação ambiental.

A percepção ambiental é diferente e varia entre os indivíduos conforme a renda, o sexo, a idade, o grau de escolaridade, as crenças, os mitos, os valores, etc. Nesse sentido, Bertoline, Possamai e Brandalise $(2009$, p. 3) afirmam que "A percepção supõe as sensações seguidas dos significados que lhes são conferidos como resultado da experiência anterior da pessoa, sendo definido por mecanismo de interpretação de informações". Além disso, os mesmos autores expõem que a percepção das pessoas varia de acordo com o perceptor e o percebido.

A importância de estudos nesta área fica evidente quando se pensa em educação ambiental e preservação ambiental. De acordo com Pedrini, Costa e Ghilardi (2010, p. 165) a partir do conhecimento das percepções "pode-se buscar a mudança de atitudes, que é um dos objetivos principais da educação ambiental para sociedades sustentáveis". Além disso, Sousa e Santos (2010, p. 463) afirmam que estes estudos "despontam como ferramentas de grande importância para a elaboração de novas metodologias de EA e avaliação constante de trabalhos já implantados".

Lynch (1999), autor da obra "A Imagem da Cidade", destaca a maneira como percebemos a cidade e as suas partes constituintes. Os elementos utilizados para construir a imagem da cidade podem ser agrupados em cinco tipos: caminhos, limites, bairros, pontos nodais e marcos, sendo os caminhos os principais elementos estruturadores da percepção ambiental para a maioria das pessoas (SABOYA, 2010).

Em cidades turísticas, a imagem turística não é a mesma imagem da cidade construída por seus moradores. A atividade turística é importante para qualquer economia, pois o fluxo constante de pessoas aumenta o consumo, a diversidade de produção de bens e serviços, gerando lucro e a geração de emprego e renda.

No entanto, os efeitos econômicos, sociais, culturais e ambientais em cidades turísticas podem gerar resultados nem sempre divididos igualmente entre os envolvidos, pois produz desigualdades na distribuição dos benefícios e dos custos. Neste sentido, a população é vítima dos efeitos do turismo e sofre com alguns impactos negativos, por exemplo, o aumento descontrolado do número de turistas e de agressões naturais e culturais (FERREIRA, 2006).

Além disso, os investimentos em infra-estrutura básica para os moradores locais no que diz respeito a saneamento, saúde, habitação, nem sempre se igualam aos investimentos em infra-estrutura turística.

\section{METODOLOGIA}

O estudo foi realizado no município de Foz do Iguaçu localizado na região Sul do Brasil e oeste do Paraná, na fronteira do Brasil com o Paraguai e Argentina (LIMA, 2010). Foz do Iguaçu é uma cidade turística que abriga uma das maiores belezas naturais, eleita uma das novas 7 maravilhas da natureza, sendo a segunda cidade brasileira mais visitada por turistas de todas as partes do mundo (FAGNANI, 2010). No entanto, a realidade vivida pelos moradores de cidades turísticas, nem sempre é a mesma observada pelos turistas que não conhecem a realidade nos bairros desses municípios.

Para a realização da presente pesquisa, foram utilizadas, de forma combinada, técnicas de questionário e entrevista, realizando aferições sobre a imagem da percepção ambiental dos munícipes de Foz do Iguaçu. A fim de coletar dados para a pesquisa, foram entrevistadas cento e sessenta e duas pessoas de diversos bairros durante o ano de 2012, visando abranger diferentes realidades. 


\section{RESULTADOS E DISCUSSÃO}

\section{Perfil dos entrevistados}

Foram aplicados 162 questionários aos habitantes do município, sendo destes 87 (54\%) do sexo masculino e (75) 46\% do sexo feminino. A idade dos participantes variou de 8 á 70 anos, havendo a predominância de sujeitos com idade entre 21 e 30 anos. Do total de entrevistados, $47 \%$ residem no município de 16 a 30 anos e a maioria relatou possuir o ensino médio e ensino superior ( $42,6 \%$ e $25,3 \%$ respectivamente). Esses dados podem ser visualizados na Tabela 1.

Tabela 1.

\begin{tabular}{l|l}
\hline \multicolumn{1}{c|}{ Questão } & \multicolumn{1}{c}{ Porcentagem } \\
\hline Sexo & Masculino - 54\% \\
& Feminino - 46\% \\
\hline Religião & Católica - 50,6\% \\
& Evangélica - $16 \%$ \\
& Nenhuma - 8,6\% \\
& Testemunhas de Jeová - 3,7\% \\
& Não respondeu - 14,2\% \\
\hline Idade & 0 a 20 anos - $9,9 \%$ \\
& 21 a 30 anos - 38,3\% \\
& 31 a 40 anos - 26,5\% \\
& 41 a 50 anos - 14,8\% \\
& 51 a 60 anos - 6,8\% \\
& 61 a 70 anos - 3,7\% \\
\hline Escolaridade & Não alfabetizado - 1\% \\
& Ensino fundamental completo - 15\% \\
& Ensino Médio completo - $42 \%$ \\
& Ensino superior completo - 25\% \\
& Especialização completa - 7\% \\
& Mestrado completo - $1 \%$ \\
& Não respondeu - 9\% \\
\hline Tempo de residência no município & $0-15$ - 21\% \\
& $16-30$ - 46,9\% \\
& $31-45$ - 16\% \\
& $46-60$ - 3,1\% \\
& Mais de 60 - 0,6\% \\
& Não respondeu - 12,3\% \\
\hline &
\end{tabular}

\section{Percepção ambiental dos entrevistados}

A maioria dos entrevistados considera o meio ambiente como áreas verdes e florestas, rios lagos e lagoas com 77,2\% e 59,3\%, respectivamente (Figura 1). Conforme é possível perceber, apenas 19,8\% dos entrevistados incluem as casas e as construções como o que entendem como o meio ambiente, relacionando meio ambiente com aspectos da natureza como os rios e as áreas verdes. Malafaia e Rodrigues (2009) estudando a percepção ambiental de jovens e adultos do ensino fundamental encontraram uma visão semelhante. Os alunos citaram como meio ambiente, os pássaros, as árvores e os rios. Já Villar et al. (2008), encontraram como resposta para o que é meio ambiente, de mais ou menos $24 \%$ dos 243 entrevistados, como o lugar onde viviam.

Quando perguntados sobre a existência de rios na cidade em que residiam, 161 pessoas $(99,4 \%)$, afirmaram que existem rios no município e apenas 1 pessoa não soube responder a esta questão, sendo esta do sexo feminino e que relatou ter frequentado a escola até o ensino médio. Em relação as áreas de preservação de florestas, a grande maioria dos entrevistados afirma ter conhecimento da existência destas no município, no entanto mais de $6 \%$ não souberam responder a esta questão.

Todos os entrevistados mostraram ter consciência de que precisamos preservar o meio ambiente 
nas suas mais variadas formas, sendo isso crucial para o homem e para a existência da natureza.

$\mathrm{Na}$ figura 2 estão demonstrados os dados obtidos quanto a forma de contribuição dos entrevistados com a poluição ambiental. A maioria citou a não separação do lixo e desperdício de água.

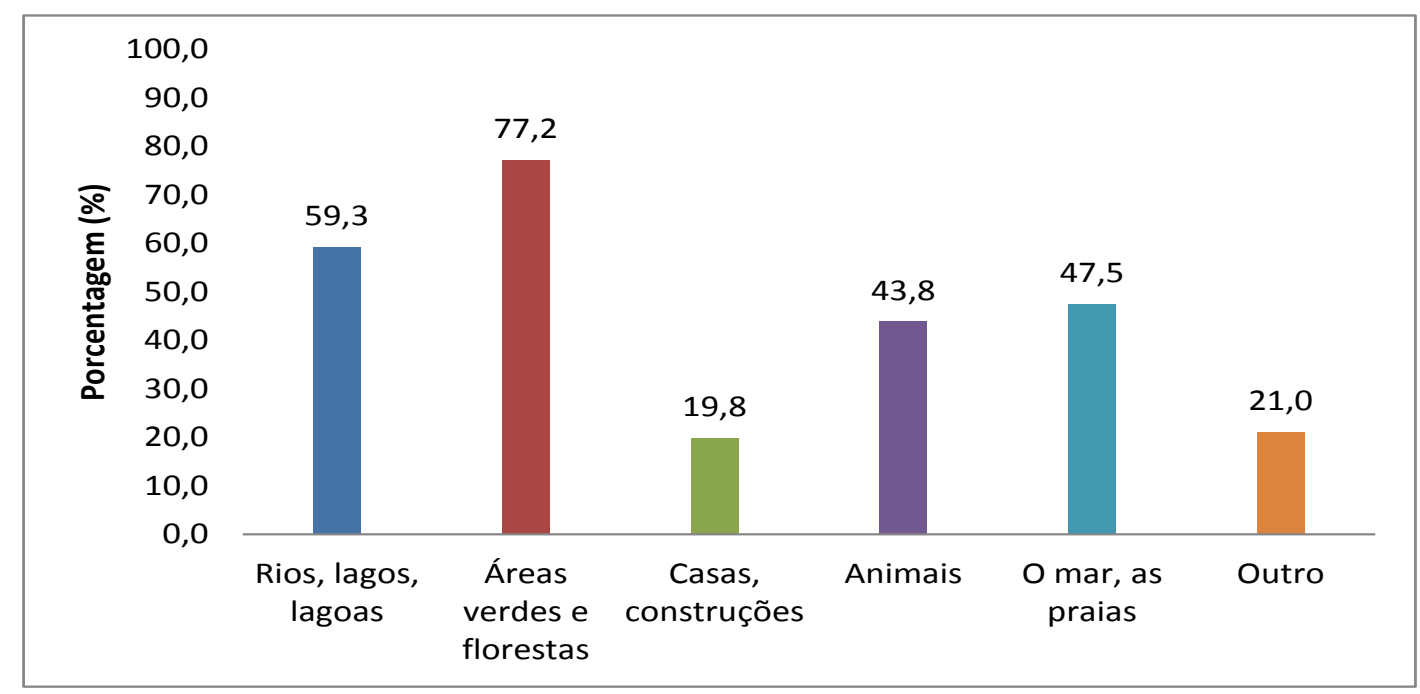

Figura 1. Percepção dos entrevistados sobre meio ambiente.

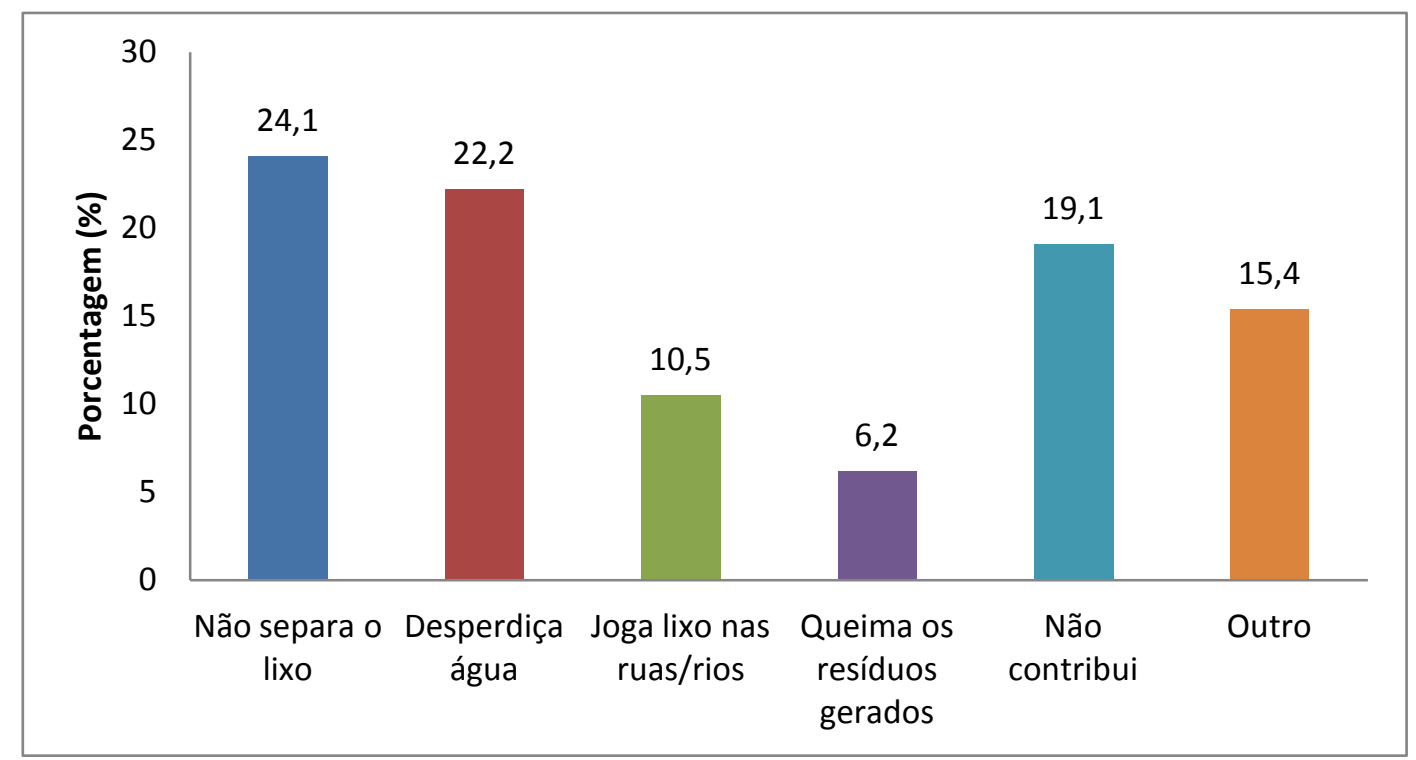

Figura 2. Forma de contribuição com a poluição ambiental

Villar et. al (2008) encontrou que a maior parte dos entrevistados também não realizava a separação dos resíduos gerados (mais de $71 \%$ ).

Brandalise et al. (2009) também, ao pesquisar universitários, encontraram que um grande número não praticava a separação do lixo. Entretanto, alguns entrevistados $(19,1 \%)$, entendem que não contribuem para a poluição ambiental.

Analisando-se o perfil escolar dos que responderam não contribuir com a poluição ambiental, os que afirmaram ter cursado até o ensino fundamental (29\%), ensino superior (27\%) e ensino médio $(25,8 \%)$ foram os que mais acreditam não contribuir de nenhuma forma com a poluição ambiental. Isso demonstra a necessidade da conscientização e inserção da educação ambiental em todos os níveis de ensino, para que a população adquira conhecimento sobre o tema e tornem-se conscientes de sua interferência e responsabilidade para com o meio ambiente. 
Ao serem questionados sobre a forma como adquirem informações sobre o meio ambiente, a televisão, como já era esperado, foi citada por mais de $60 \%$ dos entrevistados, seguido pela internet com $52,5 \%$, confirmando a importância e influência da mídia na formação do indivíduo. Fontes como livros, jornais e revistas são responsáveis apenas por 19,8\% e 37,7\%, respectivamente.

A maior parte dos entrevistados fez referência a poluição da água como o pior problema ambiental presente no município de Foz do Iguaçu. Cerca de 21,6\% relaciona a pobreza como o segundo maior problema ambiental, talvez isso reflita o saneamento básico precário que ocorre em alguns bairros e vilas. Como causadores desses problemas ambientais, os entrevistados citaram principalmente os próprios habitantes e a prefeitura (Tabela 2).

Tabela 2.

\begin{tabular}{|c|c|}
\hline Questão & Porcentagem \\
\hline $\begin{array}{l}\text { Principal problema ambiental que } \\
\text { ocorre no município }\end{array}$ & $\begin{array}{l}\text { Desmatamento - 9,9\% } \\
\text { Poluição da água - 36,4\% } \\
\text { Queimadas - } 17,9 \% \\
\text { Pobreza - } 21,6 \% \\
\text { Não há problemas - 6,8\% } \\
\text { Outros - } 25,4 \%\end{array}$ \\
\hline $\begin{array}{l}\text { Principal causador do problema } \\
\text { ambiental do município. }\end{array}$ & $\begin{array}{l}\text { Habitantes - 57,4\% } \\
\text { Prefeitura - } 21,6 \% \\
\text { Usina de Itaipu - 2,5\% } \\
\text { Turistas - } 6,2 \% \\
\text { Não há culpados - 3,1\% } \\
\text { Outro - 9,3\% }\end{array}$ \\
\hline $\begin{array}{l}\text { Formas de melhorar a qualidade } \\
\text { ambiental de Foz do Iguaçu }\end{array}$ & $\begin{array}{l}\text { Mais árvores nas áreas centrais - 29\% } \\
\text { Diminuição do no de veículos - 26,5\% } \\
\text { Diminuição das áreas de invasão - 34,6\% } \\
\text { Preservação dos rios - } 45,1 \% \\
\text { Outras sugestões - 40,7\% }\end{array}$ \\
\hline
\end{tabular}

Como forma de melhorar a qualidade ambiental do município, os entrevistados sugeriram a preservação dos rios. Castro, Silva e Silva (2009) também encontraram grande índice de indicação da contaminação da água como problema ambiental, pesquisando a percepção de donas de casa quanto a produção de petróleo.

\section{Imagem da cidade}

Em relação a imagem sócio-ambiental de Foz do Iguaçu, os entrevistados citaram as Cataratas do Iguaçu como a imagem que caracteriza a cidade e também citaram esta paisagem como o que consideravam mais singular no município e descreveram como um objeto único juntamente com a Usina de Itaipu, o Marco das Três Fronteiras e o Refúgio Biológico (Figura 3). Os entrevistados citaram também a abundância de água, as quedas, os animais e a área verde preservada citando como uma "paisagem única e maravilhosa".

Quando perguntados sobre possíveis paisagens bonitas e desagradáveis que encontravam diariamente nas ruas, as respostas mais citadas foram as avenidas que possuem arborização como áreas agradáveis. Quanto aos aspectos negativos, a coleta de lixo é citada por sua deficiência que acaba ocasio- 
nando diversos prejuízos ao meio ambiente. Em geral, os participantes responderam que encontravam bastante sujeira no trajeto, além de poucas áreas verdes e bastante trânsito. Alguns dos entrevistados que utilizam o transporte coletivo do município também citam o excesso de passageiros no seu trajeto.

Em relação a condição ambiental que a hidrelétrica gerou ao município, 62,8\% dos entrevistados acreditam que a Usina trouxe impactos e problemas ambientais ao município. Dentre os impactos mais citados pelos habitantes de Foz, o aumento da temperatura no município, o desaparecimento das Sete Quedas, a morte de animais e vegetais e a retirada de pessoas de suas casas, foram as respostas mais citadas. Apesar das repostas e da maior parte dos que responderam as questões referentes a Itaipu acreditarem que ela tenha causado algum impacto na região, muitos afirmaram que a Usina passa uma imagem ambiental bonita e agradável.

Os entrevistados foram questionados sobre as paisagens agradáveis e desagradáveis encontradas no bairro onde residem. O lixo nas ruas e em terrenos baldios foram os problemas mais citados, sendo causados pelos vizinhos e moradores que precisam ser conscientizados sobre suas ações. As favelas e invasões também foram citadas por mais de $7 \%$ dos entrevistados, como problema ambiental presente no bairro onde residiam. Contudo, com relação as paisagens que trazem algum prazer para os moradores, mais de $40 \%$ não consegue visualizar nenhuma paisagem no bairro onde moram.

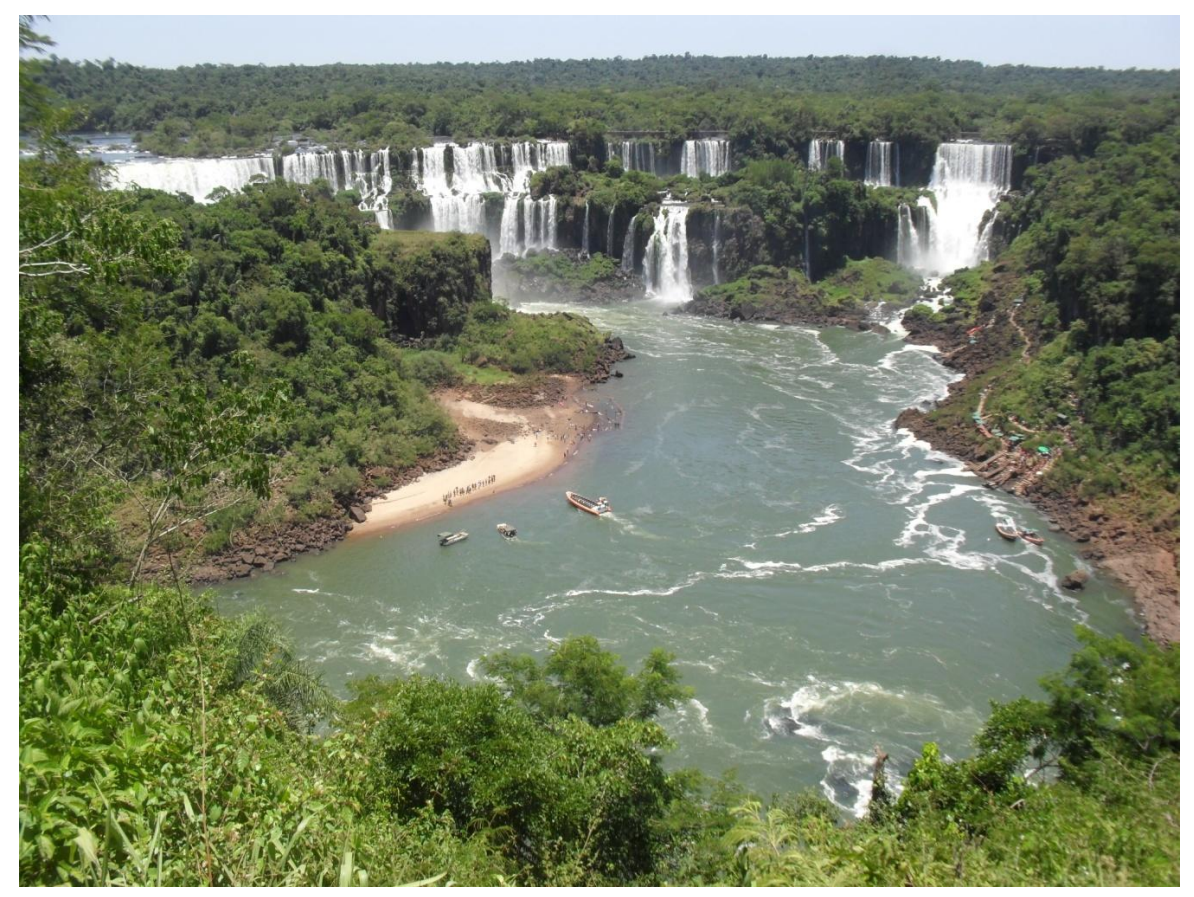

Figura 3. Cataratas do Iguaçu - Imagem lembrada pelos moradores

\section{CONCLUSÃO}

Através do presente estudo foi possível perceber a valorização do meio ambiente por parte da população, os quais acreditam que este deve ser preservado nas suas mais variadas formas. Percebese que Foz do Iguaçu é uma cidade com grande potencial, porém, apresenta diversos problemas de planejamento, estrutura e conscientização, o que acaba prejudicando muito o município.

Com este trabalho vê-se a importância da conscientização ambiental tanto na família como na escola, em todas as formas de ensino, desde a educação infantil até o ensino superior. Somente desta forma, formar-se-á indivíduos conscientes de seu papel na sociedade.

\section{REFERÊNCIAS}

ARAÚJO, J. L; BORBA, M. C. Pesquisa Qualitativa em Educação Matemática. 2. ed. Belo Horizonte: Autêntica, 2004. 
BERTOLINE, G. R. F.; POSSAMAI, O.; BRANDALISE, L. T. A Percepção dos consumidores de produtos ecologicamente corretos: estudo de caso em pequena empresa. Revista da Micro e Pequena Empresa, Campo Limpo Paulista, v. 3, n. 2, p. 99-119, 2009.

BRANDALISE, L. T. et al. A percepção e o comportamento ambiental dos universitários com relação ao grau de educação ambiental. Revista Gestão da Produção. v. 16, n. 2, p. 273-285, 2009.

BRASIL. Lei n ${ }^{\circ}$ 9795, de 27 de abril de 1999. Diário Oficial da União. Brasília, 28 abr. 1999. Disponível em: <http://www.planalto.gov.br/ccivil_03/Leis/L9795.htm>. Acesso em: 5 ago. 2012.

CASTRO, F.D.; SILVA, V. P.; SILVA, A. B. Percepção ambiental de donas de casa de Guaramaré/RN quanto a produção de petróleo e qualidade de vida. In: IV Congresso de Pesquisa e Inovação da Rede Norte e Nordeste da Educação Tecnológica. Belém, 2009. Disponível em: <http://www.ufrgs.br/seerbio/ojs/index.php/ rbb/article/view/1178>. Acesso em: 9 jul. 2012.

FAGNANI, J. P. Foz do Iguaçu: maravilha da natureza. Curitiba: Natugraf, 2010.

FERNANDES, R. S. et al. O uso da percepção ambiental como instrumento de gestão em aplicações ligadas às áreas educacional, social e ambiental. In: Congresso Brasileiro de Engenharia Sanitária e Ambiental, Campo Grande: ABES, p. 1-5, 2005.

FERREIRA, I. C. R. Os impactos sociais, econômicos e culturais do turismo em Guaramiranga-CE. Revista Turismo, 2006. Disponível em: http://www.revistaturismo.com.br/artigos/guaramiranga.html Acesso em: $25 / 01 / 2014$

INSTITUTO BRASILEIRO DE GEOGRAFIA E ESTATÍSTICA. Cidades - Foz do Iguaçu. Disponível em: <http://www.ibge.gov.br/cidadesat/painel/painel.php?codmun=410830>. Acesso em: 9 set. 2012.

LIMA, Perci. Foz do Iguaçu: no contexto da história. Foz do Iguaçu, Paraná: ed. do autor, 2010.

LYNCH, K. A imagem da cidade. Lisboa: ed. Edições 70, 1999.

MALAFAIA, Guilherme. RODRIGUES, A. S. de L. Percepção ambiental de jovens e adultos de uma escola de ensino fundamental. Revista Brasileira de Biociências. Porto Alegre, v. 7, n. 3, p. 266-274, 2009.

MILLER JR, G. T. Ciência Ambiental. São Paulo: Cengage Learning, 2008.

PEDRINI, A.; COSTA, E. A.; GHILARDI, N. Percepção ambiental de crianças e pré-adolescentes em vulnerabilidade social para projetos de educação ambiental. Revista Ciência \& Educação, vol. 16, n. 1, p. 164-179, 2010.

PHILIPPI JR, A. PELICIONI, M. C. F. Educação Ambiental e sustentabilidade, Barueri: Manole, 2005.

PHILIPPI JR, A.; ROMÉRO, M. A.; BRUNA, G. C. Curso de gestão ambiental. Barueri: Manole, 2004.

RUSCHEINSKY, A. Educação Ambiental: Abordagens Múltiplas. Porto Alegre: Artmed, 2002.

SABOYA, R. Kevin Lynch e a imagem da cidade. Urbanidades, 2008. Disponível em: http://urbanidades.arq. br/2008/03/kevin-lynch-e-a-imagem-da-cidade/ Acesso em 25/01/2014

VILLAR, L. M et al. A Percepção Ambiental entre os Habitantes da Região Noroeste do Estado do Rio de Janeiro. Revista de Enfermagem Escola Anna Nery, v. 12, 2008. 